\title{
Application of CSAMT and high resolution seismic prospecting in geothermal Survey in Guanting
}

\author{
Chenglin Yao ${ }^{1, a^{*}}$, Zhongjun Deng ${ }^{1, b}$, Yongmei Jia ${ }^{1, \mathrm{c}}$ and Yubo Yang ${ }^{1, \mathrm{~d}}$ \\ ${ }^{1}$ Beijing IWHR Corporation, China Institute of Water Resources and Hydropower Research, Beijing \\ 100048, China \\ ayaocl@iwhr.com, ${ }^{b}$ dengzj@iwhr.com, ${ }^{\text {Cjiaym@iwhr.com, }{ }^{d} y a n g y b @ i w h r . c o m ~}$
}

Keywords: Geothermal; CSAMT; Seismic exploration; Fracture structure

Abstract. The distribution of geothermal resources is influenced by the geological structure. It is of great significance to find the factors which influence the heat source. On the other hand, geothermal causes the local temperature anomaly, and further causes the change of the physical properties of the target rocks, which provides an important physical premise for the geophysical exploration. In this paper, the application of geophysical prospecting method in geothermal exploration will be introduced by an example.

\section{Introduction}

Geothermal is a valuable green energy. In recent years, the utilization of geothermal resources is more and more wide, and its value is also more concerned. Take Hebei Province Huailai County Guanting town Guanting Lake as an example, study of controlled source audio frequency magnetotelluric method and high resolution seismic exploration geophysical methods in geothermal exploration in the application. According to the comprehensive geophysical data, by analyzing the distribution characteristics of each fracture and combining with regional geological data, we can evaluate the potential of the geothermal resources in the region.

\section{Regional geological conditions}

\section{Tectonic}

The district is located in the middle section of the northern margin of North China platform, Chongli-Chicheng deep faults in the south, in China and the DPRK quasi platform (first-order tectonic units) the Yanshan platform fold belt (class II structural units) Xuan dragon compound syncline (grade III structural units of Zhuolu fold beam (IV grade tectonic units), see Fig.1.
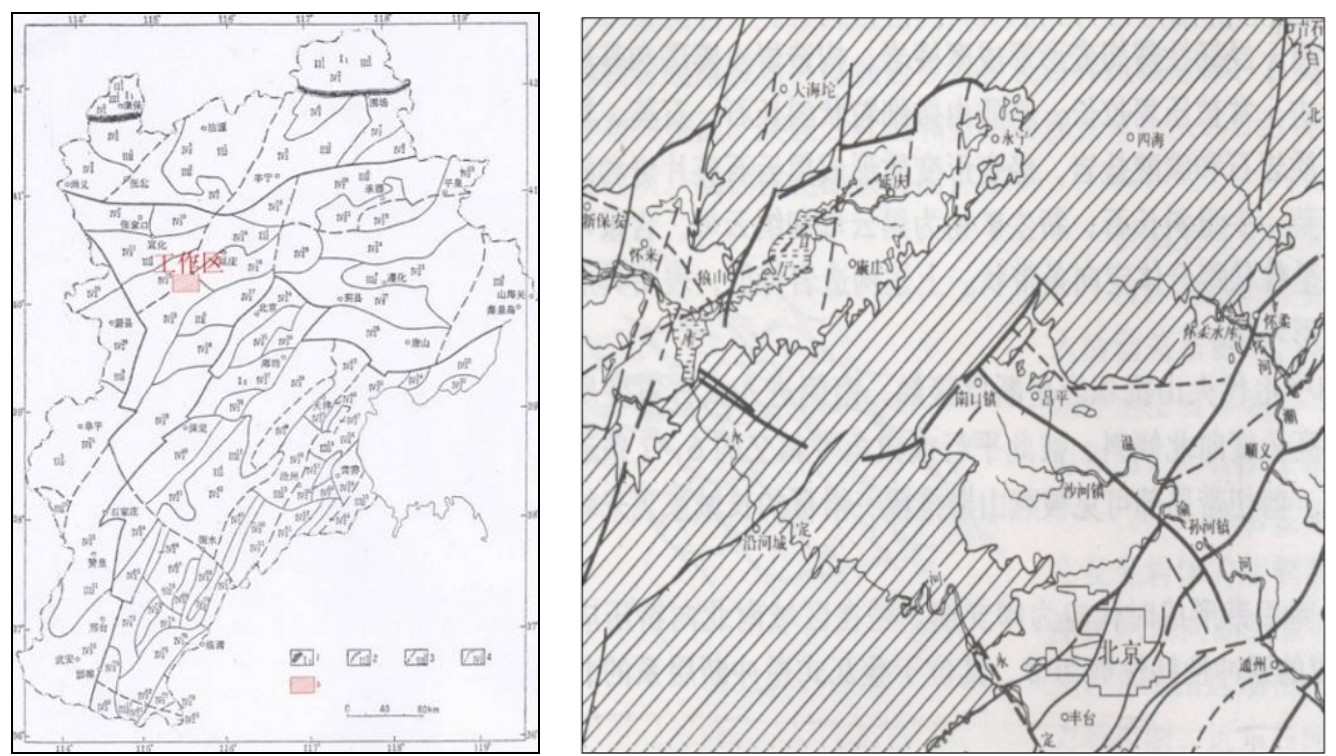

Fig.1 Distribution of tectonic units

Fig.2 Main active fault distribution in Guanting area 


\section{Crack}

There are Big City NE fault and Shi Zhuang NW fault near the work area, both are active faults, as shown in Fig.2.

The geophysical exploration in the work area finds three hidden faults, F3 direction can be inferred for the North East, the inclination is steep. These faults are normal faults, may be Yanhuai basin regional faults or a secondary fault.

\section{Seismic geological condition}

Surface of the exploration area consist of loose alluvial, flood area and wind deposits, which are mainly the clayey soil, gravel and coarse, medium sand, a cross layer output, horizontal bedding development. Alluvial gravel, coarse sand gravel, sand, sand and sand sticking. Lithology of Diluvium is yellow white yellow clayey sand, sandy clay clip sand and gravel, shallow seismic geological condition. Deep Cenozoic in this area and the overlying dolomite of Wumishan formation is a reflection of a better interface, so deep seismic geological condition is good.

\section{Electrical characteristics}

In quaternary resistivity changes larger, the pattern is: Quaternary resistivity change with size of quaternary lithology, and also closely related to the temperature and humidity. The Quaternary strata and the underlying bedrock has obvious electric difference. From the above analysis, it can be seen that there is obvious difference among different strata (lithology), and the test area has the prerequisite for the exploration of the controlled source audio MT (CSAMT).

\section{Geological conditions of the test area}

The work area is located in the middle and low temperature geothermal area in the Cenozoic faulted basin, Huailai basin. The geothermal field was exposed and the water temperature varies from 25 to $80^{\circ} \mathrm{C}$. The temperature of bedrock fissure confined water can be more than $80^{\circ} \mathrm{C}$.

\section{Heat source}

In the area of the fault zone or the impact zone, that is, the deep geothermal fluid to provide a good guide for water conduction, but also to provide a good storage space for geothermal water.

\section{Heat reservoir}

On the grounds of the Cenozoic rift basin geological model, underground hot water in the "basement" Middle Proterozoic carbonate weathering karst fractured aquifer, become the geothermal reservoir proposed geothermal wells of geothermal resources.

\section{Geothermal conceptual model}

Geothermal resources insulating cover layer is thin, marginal basin of the Middle Proterozoic strata are exposed out of surface, receiving the recharge of precipitation and surface water, and the fracture zone formation of hot and cold water mixed convection constitute for the type of medium low temperature geothermal resources.

\subsection{Characteristics of geothermal resources}

According to the analysis of geothermal well data, the characteristics of geothermal resources are as follows:

1. The lower temperature gradient of the cover layer and the geothermal reservoir, the lower temperature of the underground water outlet.

2. The heat storage layer of underground water is rich, single well flow.

3. The chemical type of groundwater in the underground hot water is the type of heavy soda (calcium).

4. Underground water mineralization degree is low.

\section{Inference explanation}

\section{Controllable source audio MT interpretation}

According to the apparent resistivity map (Fig.3), the apparent resistivity of each section shows a trend that with the increasing of depth, the apparent resistivity value is getting higher. However, the 
apparent resistivity of the different section is not the same as that of the geological structure at the same location:

(1) According to the variation characteristics of apparent resistivity, 0 to $2000 \mathrm{~m}$ depth range is divided into three large electrical layers: the low resistivity layer, the resistivity is generally less than $50 \mathrm{ohm}$ meters; the middle resistivity layer, the resistivity is generally between 600 and $140 \mathrm{ohm}$ meters, the high resistivity layer, the resistivity is generally greater than $140 \mathrm{ohm}$ meter. The lateral continuity of each layer is good, but its thickness varies, the first reason of the change is the change of lithology, and the second is the influence of the fracture structure.

(2) According to the geological characteristics of this area, the shallow low resistivity layer roughly corresponding to the quaternary; in the middle of the resistance layer is roughly corresponding to the Wumishan formation ( $\mathrm{Jxw})$; deep high resistance value layer corresponding to the great wall system higher than that of Zhuang $(\mathrm{CHg})$

(3) The fault zone is generally presented as a low resistivity zone, which is "V" shaped distribution in the section. According to the variation of resistivity, the two F1, F2, fracture are almost vertical.

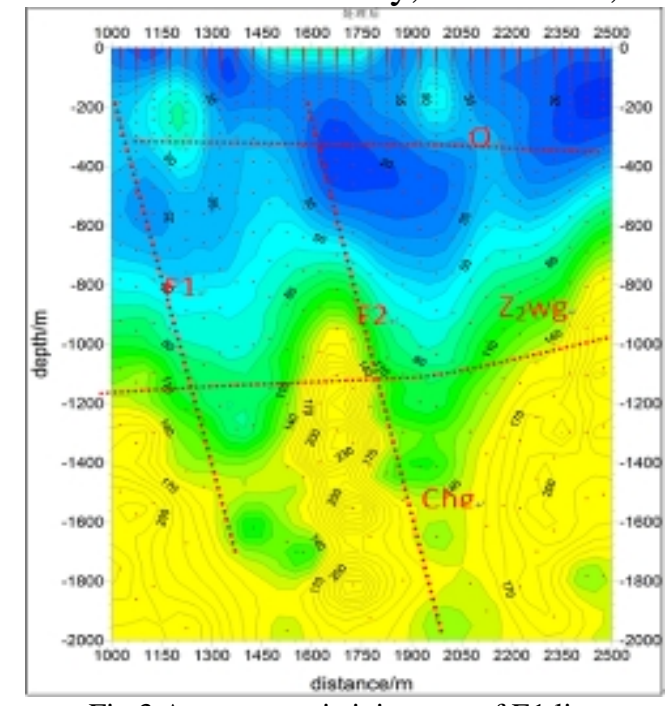

\section{Shallow seismic interpretation}

Fig.3 Apparent resistivity map of E1 line

From the pre stack depth migration section of E1 line, we can see that there are several groups of reflection wave group, see Fig.4. 200m depth is obvious reflection horizons good continuity, combined with the velocity profile of the E1 Line speculation as the lower boundary of the Quaternary, quaternary compressional wave velocity is about $2000 \mathrm{~m} / \mathrm{S}$. This layer is continuous in the transverse direction and distributed horizontally. The lithology is mainly composed of clayey soil, alluvial, pluvial sediments, aeolian material, gravel and coarse, medium sand was interbedded output, horizontal bedding development. At the depth of $200 \mathrm{~m}$, the formation of the strata is to the south, the dip angle is about 20 degrees, and there are two faults, which are named F3 and F2 (see below). Combined with the velocity profile, the fault is a normal fault, which is gradually enlarged from shallow to deep, inclined to the North West, the shallow dip angle is close to 80 degrees.

From the E1 line seismic longitudinal wave velocity profile (Fig.5) can be seen in the pile number 1510 and 2050, respectively, there is a larger " $\mathrm{V}$ " type low speed belt. The longitudinal wave velocity of the former has obvious change in the deep range of $200 \sim 1000 \mathrm{~m}$, the middle is low, the two sides are high. The latter "V" - type low speed with depth, in the range of $200 \sim 800 \mathrm{~m}$ has a significant change in the middle and low speed, on both sides of high-speed. The position of the low velocity zone is located in the two positions, which is consistent with the fault location shown in the pre stack depth migration section and the electrical section. 


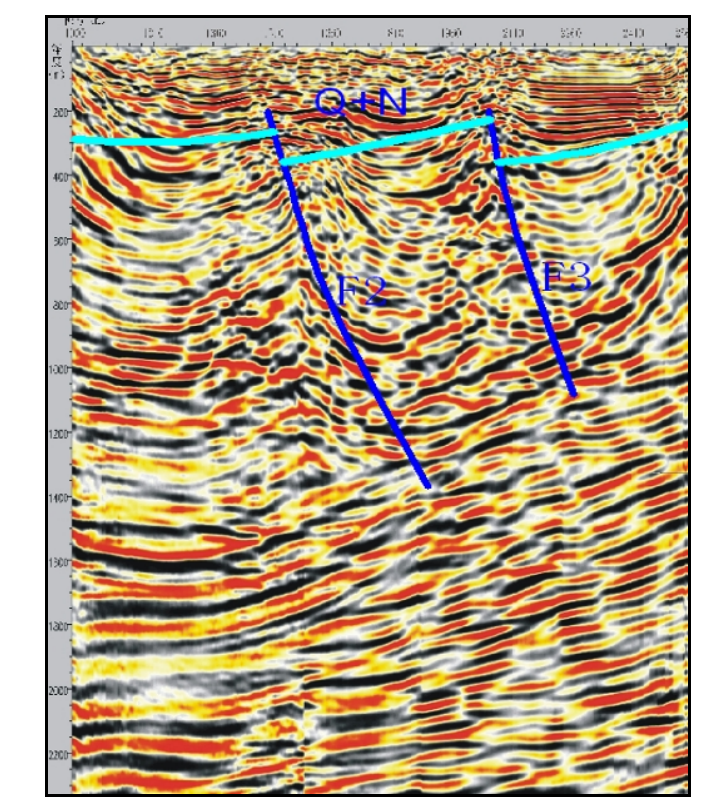

Fig.4 Velocity migration section of 2D seismic prestack

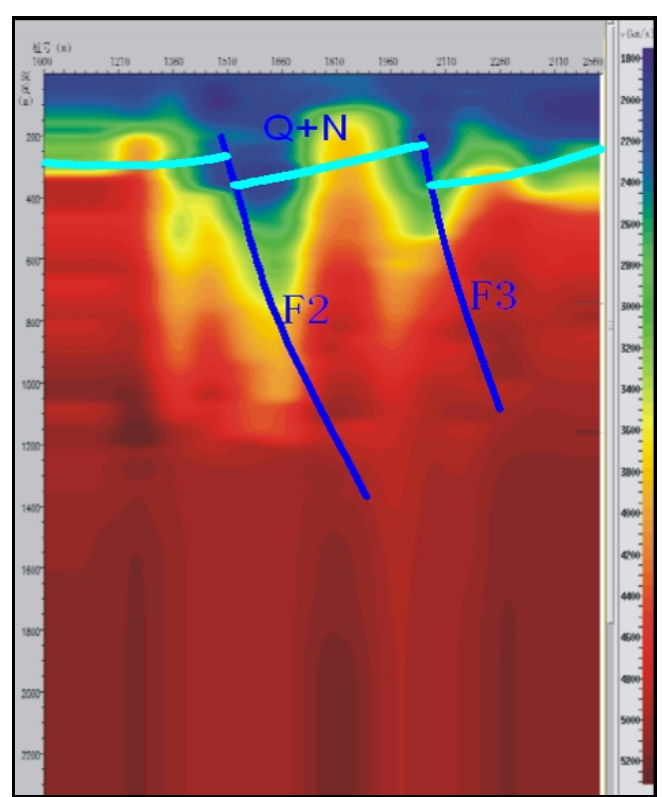

Fig.5 2D seismic $\mathrm{P}$ wave profile

\section{Conclusions}

This work basically found out the distribution of the fault and the vertical strata in the area, controlling the depth of $2000 \mathrm{~m}$, and providing the basic data for the development of the geothermal well in the area. Based on the analysis of the CSAMT and 2D seismic data, combining with geological background, the distribution characteristics of the faults in space are analyzed. In the following stage, the exploration of the earth is verified by the drilling operation, which is based on the low resistance of the thermal reservoir and the fracture zone or the impact zone.

\section{References}

[1] Cao Yongan, Jiang Haihao, Comprehensive geophysical prospecting method in application of peripheral geothermal exploration in Anshan City, geological prospecting series, 2013, 28 (1)

[2] Deng Guoquan, Cheng Yuntao, CSAMT in Fujian, the application of the, 2011, 35 (6): $751 \sim 757$.

[3] Hu Ning, Liang Hong Zhang, Haifa, The application of integrated geophysical prospecting method in geothermal exploration in Jiaxing, geophysical and geochemical exploration, 2011,35 (3): 319 324.: 11 13.

[4] Wang Bin, He Shihao, Li Baixiang, Analysis of geothermal geological conditions in Xining basinfrom the geophysical field information, the Western Seismological Journal, 2011, 33 (2): 149 165.

[5] Wang Wei, The practice and research of underground engineering of Geothermal Development Zone, water conservancy and hydropower technology, 2014, 45 (4): 87 92.

[6] Zhao Gang, Wang Jun, et al. Study on the normal dynamic characteristics of geothermal, earthquake, 29, 2009 (3): 109 116.

[7] Wu Jixin, Comprehensive utilization of various technical methods in geothermal exploration, groundwater, 2013, 35 (3): 105 109. 